\title{
Journal of Bacteriology and

\section{Rapid Detection of NDM, VIM, KPC and IMP Carbapenemases by Real-Time PCR}

Ewa Kosykowska*, Tomasz Dzieciątkowski and Grażyna Młynarczyk

Chart and Department of Medical Microbiology, Medical University of Warsaw, Warsaw, Poland

"Corresponding author: Ewa Kosykowska, Chart and Department of Medical Microbiology, Medical University of Warsaw, Warsaw, Poland, Tel: +48226282739; E-mail: ewa.kosykowska@wum.edu.pl

Received date: November 24, 2016; Accepted date: December 20, 2016; Published date: December 30, 2016

Copyright: @ 2016 Ewa K, et al. This is an open-access article distributed under the terms of the Creative Commons Attribution License, which permits unrestricted use, distribution, and reproduction in any medium, provided the original author and source are credited.

\begin{abstract}
Carbapenems are the most potent beta-lactams, characterized by broad spectrum of activity against Gramnegative and Gram-positive bacteria. Unfortunately, the dynamic dispersal of carbapenem resistance among nonfermentative bacteria and Enterobacteriaceae is an over-increasing problem and might lead to dangerous limitation of treatment options. Among three different mechanisms of resistance the enzyme production is of special importance. In this case, only one small gene is enough to express carbapenem resistance. The carbapenemase genes are often a part of integrons, which carry diverse arrays of resistance gene cassettes and just one transfer event is enough to disseminate multidrug resistance. Moreover, carbapenemase genes are often located within Mobile Genetic Elements. For these reasons carbapenemases are the most epidemiologically importance. Early detection and identification of carbapenemase producers among clinical isolates can avoid nosocomial infections. We have developed a multiplex Real-Time PCR assay based on the TaqMan technology for rapid detection and identifications of the most common carbapenemases in Europe NDM, VIM, KPC and IMP. There were tested 31 isolates Enterobacteriaceae $(n=15)$ and non-fermentative Gram-negative bacillary $(n=16)$, which acquire NDM, VIM, KPC, IMP, GIM or OXAs carbapenemases. The whole elaborated experiment, including DNA isolation and PCR cycling, lasts up to $2 \mathrm{~h}$.
\end{abstract}

Keywords: Carbapenemases detection; Real-Time PCR; NDM; VIM; KPC; IMP

\section{Introduction}

Emerging and dissemination of carbapenem-hydrolysing betalactamases among Enterobacteriaceae and non-fermentative Gramnegative bacillary such as Pseudomonas spp. or Acinetobacter baumannii over past decade is serious issue in the hospital environment. It is worthy to mention that carbapenemase producing organisms (CPOs) have primarily been recognized in hospitals but currently they are more and more common cause as well community infections [1]. Currently known mechanisms for carbapenem resistance among Gram-negative bacteria, involve decreased permeability by porins modifications, efflux pumps, increased natural cephalosporinase activity and the most frequent carbapenemase producing [2-4]. The carbapenemases hydrolyse almost all betalactams, are resistant to all therapeutically useful inhibitors and are coproduced with other beta-lactamases [5]. Moreover, carbapenemase genes are often a part of integrons, which carry diverse arrays of resistance gene cassettes. The most worrisome is the situation when such integron is located within some Mobile Genetic Elements (MGEs, transposons or transmissible plasmids). In this case just one transfer event is enough to disseminate multidrug resistance [1].

The most common carbapenemases in the world are NDM, VIM and IMP belonged to molecular class $\mathrm{B}$ and $\mathrm{KPC}$, serine enzyme pertained to molecular class A [5].

Prevention of the dissemination of carbapenem resistant bacteria is of the utmost importance. Accurately identifying in the clinical laboratory is the first step in protection [1]. The purpose of the study has been to create the rapid method to detect such organisms. We have developed a multiplex real-time PCR (RT-PCR) assay, using TaqMan chemistry to detect just those species which possess some of the most frequent carbapenemases' types VIM, IMP, NDM and/or KPC.

\section{Materials and Methods}

\section{Bacterial strains}

Thirty-one reference bacterial strains were obtained from the collection of the Chair and Department of Medical Microbiology, Medical University of Warsaw and used for detection in culture in order to validate the novel detection assay of blaviM, blaIMP, blaNDM, blaKPC genes. All of the strains were clinical isolates tested by conventional PCR for several beta-lactamases genes (blaVIM, blaIMP, blaGIM, blaKPC, blaNDM; in case of Acinetobacter spp. also: blaOXA-23, blaOXA-24, blaOXA-51, blaOXA-58) [6-9]. The only one exception was NDM-1-positive $E$. coli DH5a created by synthesis of the blaNDM-1 gene (Epoch Life Science, USA) and transformation of the plasmid encoding this synthesized gene (pNDM_EK) into E. coli DH5a. Two strains ( $P$. aeruginosa WUM_5 and $P$. aeruginosa WUM_6) came from the National Medicines Institute. All bacterial strains are described in details in Table 1. MICs were determined using Etest (bioMerieux).

\section{DNA extraction}

DNA was isolated from bacterial colonies using the boiling lysis method. Strains were streaked onto Mueller Hinton (MH) agar and grown overnight at 37C. A loopful of bacterial growth was suspended in $100 \mu \mathrm{l}$ of sterile distilled water, incubated at room temperature for 5 
Citation: Ewa K, Tomasz D, Grazyna M (2016) Rapid Detection of NDM, VIM, KPC and IMP Carbapenemases by Real-Time PCR. J Bacteriol

Page 2 of 5

$\mathrm{min}$, and then boiled for $10 \mathrm{~min}$. After centrifugation at $13200 \mathrm{rpm}$ for $10 \mathrm{~min}$, the pellet was discarded and the supernatant containing DNA was used directly for PCR or stored at $-20^{\circ} \mathrm{C}[6]$.

\section{Analytical specificity}

Analytical specificity for each assay was verified using the following comprehensive panel of different beta-lactamases producers. We used five different species of Enterobacteriaceae. Escherichia coli, Enterobacter cloacae, Klebsiella oxytoca, Klebsiella pneumoniae, Serratia marcescens and four species of non-fermentative Gramnegative bacillary: Acinetobacter baumannii, Acinetobacter junii, Pseudomonas aeruginosa and Pseudomonas putida. All of them were beta-lactamases producers (described in details in Table 1).

\section{Design of primers and TaqMan probes}

All primers and probes were designed with using LightCycler Probe Design Software 2.0 (Roche Diagnostics). Reference sequence for each of five genes was assembled from GeneBank (accession numbers: JF966383.1; JX104759.1; GU831553.1; AB182996.1; JQ060896.1). Sequence specificity was confirmed in sillico by nucleotide-nucleotide search in the National Centre for Biotechnology Information (NCBI) database (http://www.ncbi.nlm.nih.gov/BLAST/). The detailed sequences of used primers and probes are described in Table 2.

\begin{tabular}{|c|c|c|c|c|c|c|c|c|}
\hline \multirow[b]{2}{*}{ Isolate no. } & \multirow[b]{2}{*}{ Bacterium } & \multirow[b]{2}{*}{ Genotype a } & \multicolumn{4}{|c|}{ MIC $[\mu \mathrm{g} / \mathrm{ml}]$} & \multicolumn{2}{|c|}{ Multiplex RT-PCR results } \\
\hline & & & $\mathrm{DOR}^{\mathrm{b}}$ & ETP b & $\mathrm{IMP}^{\mathrm{b}}$ & $M R^{b}$ & $530 \mathrm{~nm}$ & $610 \mathrm{~nm}$ \\
\hline 1 & E. coli WUM_1 & blaNDM-1 & ND & ND & ND & ND & + & - \\
\hline 2 & K. pneumoniae WUM_1 & blaNDM & 3 & ND & 16 & 4 & + & - \\
\hline 3 & E. coli WUM_2 & blaKPC & 0,75 & 0,5 & 4 & 0,5 & - & + \\
\hline 4 & E. coli WUM_2 & blaKPC & 24 & $>32$ & $>32$ & $>32$ & - & + \\
\hline 5 & K. oxytoca WUM_1 & blaVIM, blaKPC & 2 & 8 & 12 & 2 & - & + \\
\hline 6 & K. oxytoca WUM_2 & blaKPC & 1 & 1,5 & 0,5 & 1 & - & + \\
\hline 7 & K. pneumoniae WUM_2 & blaKPC & $>32$ & $>32$ & 16 & $>32$ & - & + \\
\hline 8 & K. pneumoniae WUM_3 & blaKPC & $>32$ & $>32$ & $>32$ & $>32$ & - & + \\
\hline 9 & K. pneumoniae WUM_4 & blaKPC & $>32$ & $>32$ & $>32$ & $>32$ & - & + \\
\hline 10 & K. pneumoniae WUM_5 & blaKPC & $>32$ & $>32$ & $>32$ & $>32$ & - & + \\
\hline 11 & K. pneumoniae WUM_6 & blaKPC & $>32$ & $>32$ & $>32$ & $>32$ & - & + \\
\hline 12 & K. pneumoniae WUM_7 & blaKPC & $>32$ & $>32$ & $>32$ & $>32$ & - & + \\
\hline 13 & K. pneumoniae WUM_8 & blaKPC & $>32$ & $>32$ & $>32$ & $>32$ & - & + \\
\hline 14 & E. cloacae WUM_1 & blaVIM & 0,75 & 4 & 1,5 & 1,5 & - & + \\
\hline 15 & P. aeruginosa WUM_1 & blaVIM-2 & 16 & ND & 12 & 6 & - & + \\
\hline 16 & P. aeruginosa WUM_2 & blaVIM & $>32$ & ND & $>32$ & $>32$ & - & + \\
\hline 17 & P. aeruginosa WUM_3 & blaVIM & 32 & ND & $>32$ & $>32$ & - & + \\
\hline 18 & $P$. aeruginosa WUM_4 & blaVIM & 32 & ND & $>32$ & 32 & - & + \\
\hline 19 & P. putida WUM_1 & blaVIM & 16 & ND & $>32$ & $>32$ & - & + \\
\hline 20 & S. marcescens WUM_1 & blaVIM & $>32$ & $>32$ & $>32$ & $>32$ & - & + \\
\hline 21 & $P$. aeruginosa WUM_5 & blalMP-1 & $>32$ & ND & $>32$ & $>32$ & + & - \\
\hline 22 & P. aeruginosa WUM_6 & blaGIM-1 & $>32$ & ND & $>32$ & $>32$ & - & - \\
\hline 23 & A. baumannii WUM_1 & blaOXA-24, blaOXA-51 & $>32$ & ND & $>32$ & $>32$ & - & - \\
\hline 24 & A. baumannii WUM_2 & blaOXA-24, blaOXA-51 & $>32$ & ND & $>32$ & $>32$ & - & - \\
\hline 25 & A. baumannii WUM_3 & blaOXA-24, blaOXA-51 & $>32$ & ND & $>32$ & $>32$ & - & - \\
\hline 26 & A. baumannii WUM_4 & blaOXA-51, blaOXA-58 & 32 & ND & 32 & 32 & - & - \\
\hline
\end{tabular}


Citation: Ewa K, Tomasz D, Grazyna M (2016) Rapid Detection of NDM, VIM, KPC and IMP Carbapenemases by Real-Time PCR. J Bacteriol Parasitol 7: 299. doi:10.4172/2155-9597.1000299

Page 3 of 5

\begin{tabular}{|l|l|l|l|l|l|l|l|l|}
\hline 27 & A. baumannii WUM_5 & blaOXA-51, blaOXA-58 & 12 & ND & 32 & 32 & - & - \\
\hline 28 & A. baumannii WUM_6 & blaOXA-51 & 4 & ND & 6 & 8 & - & - \\
\hline 29 & A. baumannii WUM_7 & blaOXA-51, blaOXA-58 & 24 & ND & $>32$ & 32 & - & - \\
\hline 30 & A. baumannii WUM_8 & blaOXA-51 & 32 & ND & 32 & 32 & - & - \\
\hline 31 & A. junii WUM_1 & blaOXA-58, blaVIM & 2 & ND & 16 & 4 & - & + \\
\hline
\end{tabular}

Table 1: Results of multiplex RT-PCR and MICs of bacterial isolates used in this study. ${ }^{\text {a }}$ Genotype was determined by conventional PCR in our labalatory; ${ }^{b}$ DOR - doripenem; ETP - ertapenem; IMP - imipenem; MER - meropenem; ND - MICs not determined because of natural resistance for ertapenem Pseudomonas spp. and Acinetobacter spp. and in case of nonclinical isolate blaNDM-1 positive strain; + positive result; (-) negative result.

\section{Real-Time PCR}

Investigations were performed using amplification mixture TaqMan Master Kit (Roche Diagnostics). Besides chemicals supplied by kit producer, reaction mixture contained $1 \mu \mathrm{l}$ of template DNA, $1,5 \mu \mathrm{M}$ of each probe, 1,$75 ; 2$ or $2,25 \mu \mathrm{M}$ of adequate primers (as described in Table 2) in a final volume of $10 \mu$ l. The best results of amplification were obtained with: activation of thermostable hot-start DNA polymerase for $10 \mathrm{~min}$ at $95^{\circ} \mathrm{C}$, followed by 40 cycles comprising: denaturation $\left(10 \mathrm{~s}\right.$ at $\left.95^{\circ} \mathrm{C}\right)$, primers annealing $\left(10 \mathrm{~s}\right.$ at $\left.60^{\circ} \mathrm{C}\right)$ and strand elongation $\left(15 \mathrm{~s}\right.$ at $\left.72^{\circ} \mathrm{C}\right)$. After the end of cycling, material was cooled down to $40^{\circ} \mathrm{C}$ for $60 \mathrm{~s}$. Fluorescence levels were measured at wavelengths: $530 \mathrm{~nm}$ (FAM dye) and $610 \mathrm{~nm}$ (LC-Red 610 dye). The limit of detection (LOD) of each assay was determined by analysis of serial decimal dilutions of used DNA in range 101-106 copies. Each dilution was prepared and analyzed in six independent replications. Probity analysis was used to calculate the LOD concentration [10].

All described experiments were performed in two independent repetitions, using LightCycler 2.0 instrument (Roche Diagnostics).

\section{Interpretation of results}

A sample was considered positive by RT-PCR if it crossed the threshold before a crossing point $(C P)$ of 35 cycle and negative if the $C p$ was greater than 35 . Positive result at wavelength $530 \mathrm{~nm}$ (FAM dye) stated the presence of blaIMP or blaNDM, whereas positive result at wavelength $610 \mathrm{~nm}$ (LC-Red 610 dye) meant the presence of blaVIM or blaKPC.

\begin{tabular}{|c|c|c|c|c|c|}
\hline Target & Primer/probe name & Sequence $\left(5^{\prime} \rightarrow 3^{\prime}\right)$ & $\begin{array}{l}\text { Amplicon size } \\
\text { (bp) }\end{array}$ & Concentration $[\mu \mathrm{M}]$ & $\begin{array}{l}\text { Reference } \\
\text { sequence }^{b}\end{array}$ \\
\hline \multirow[b]{3}{*}{ blaVIM } & VIMf & TCTCCACGCACTTTCATGAC & 124 & 2 & JF966383.1 \\
\hline & VIMr2 & GTGGGAATCTCGTTCCCCTC & & 2 & \\
\hline & s_qVIM & LC.red 610 -GGCAACGTACGCATCACCGTC- BHQ-2 a & & 1,5 & \\
\hline \multirow[b]{3}{*}{ blaKPC } & KPCf & ATATCTGACAACAGGCATGAC & 95 & 1,75 & JX104759.1 \\
\hline & $\mathrm{KPCr}$ & CСАAСТССТTСАGCAACAAA & & 1,75 & \\
\hline & s_qKPC & LC.red 610 -AATACAGTGATAACGCCGCCG- BHQ-2 & & 1,5 & \\
\hline \multirow[b]{3}{*}{ blalMP-1 like } & IMP1f & GGCTTAATTCTCGATCTATCCC & 114 & 1,75 & GU831553.1 \\
\hline & IMP1r & CTAGCCAATAGTTAACTCCGC & & 1,75 & \\
\hline & s_qIMP1 & FAM -GACGGTAAGGTTCAAGCCACAAAT- BHQ-1 & & 1,5 & \\
\hline \multirow[b]{3}{*}{ blalMP-2 like } & IMP2f & TAGAGTGGCTTAATTCTCAATCTATTCC & 120 & 2 & AB182996.1 \\
\hline & IMP2r & CTAGCCAATAACTAACTCCGC & & 2 & \\
\hline & s_qIMP2 & FAM -AACTTCTTAAAAAAGACGGTAAGGTGCA- BHQ-1 & & 1,5 & \\
\hline \multirow[b]{3}{*}{ blaNDM } & NDM1f2 & GATCCTCAACTGGATCAAGC & 128 & 2,25 & JQ060896.1 \\
\hline & NDM1r2 & CATTGGCATAAGTCGCAATC & & 2,25 & \\
\hline & s_qNDM & FAM -GACTCACGCGCATCAGGACAA- BHQ-1 & & 1,5 & \\
\hline
\end{tabular}

Table 2: Primers and probes used in this study. ${ }^{a}$ Probes' 5 ' reporter and 3' quencher dyes are bolded. ${ }^{b}$ Gene Bank accession no. 


\section{Results}

Designed primers and probe of the blaKPC amplicon in silico show total identity to all 12 alleles (blaKPC-2 to blaKPC-13). Likewise, NDM1f, NDM1r primers and s_qNDM probe are identical to all known blaNDM (bla NDM-1-7) alleles. Amplicon VIM covers most of the 33 alleles but not all. However, the most common VIM alleles are detectable. VIMf, VIMr primers and s_qVIM probe are identical to regions of blaVIM-1, 2, 4, 5, 8, 9, 10, 12, 14-17, 19-33 alleles. blaVIM-3, $6,7,11,13$ alleles have from one to five single nucleotide polymorphisms (SNPs) within these regions which are covered by those three oligonucleotides. blaVIM-18 allele has $12 \mathrm{nt}$ deletion in the region which covers VIMr primer. blaIMP-like genes are much more diverse than the others and we decided to design two amplicons. Such solution allowed to detect the majority of the most frequent blaIMP alleles. IMP-1f, IMP-1r primers and s_qIMP1 probe are identical to blaIMP-1, 3, 6, 10, 25 and 30 alleles. IMP-2f, IMP-2r primers and s_qIMP2 probe are identical to blaIMP-2, 8, 19, 20 and 24 alleles.

\section{Analytical specificity}

The specificity of the primers and probes for the detection of all investigated genes were evaluated by the BLAST search program, available at www.ncbi.nlm.nih.gov. No matches to the primers and probe sequences other than those which were investigated were found.

Additionally, to verify analytical specificity, the multiplex RT-PCR assay was checked in 31 DNA templates from nine different Gramnegative species, beta-lactamases producers (described in details in Table 2) and the results are in accordance with expected. No crossreactivity or nonspecific amplification was observed for any of the assays tested with these tested organisms.

After positive result, it is recommended to conduct the next RTPCR with single pair of primers (monoplex RT-PCR) to find out which exactly carbapenemase tested isolate contains. For example, if tested strain revealed signal on $610 \mathrm{~nm}$, it is worthy to conduct two independent reactions with KPC primers and probes and with VIM oligonucteotides. Differentiation of carbapenemase type is also possible by cheaper and time-consuming methods such as phenotypic tests. The results of LOD in developed RT-PCR assays, determined in DNA copies per reaction tube are shown in Table 3 (supplementary information).

\begin{tabular}{|l|l|l|}
\hline $\begin{array}{l}\text { Detected gene } \\
\text { in a given RT- } \\
\text { PCR assay }\end{array}$ & LOD (DNA copies/reaction) & $\begin{array}{l}\text { 95\% confidence interval } \\
\text { (DNA copies/reaction) }\end{array}$ \\
\hline bla KPC & 107 & $81-129$ \\
\hline bla IMP-1 & 56 & $44-67$ \\
\hline bla NDM-1 & 194 & $175-231$ \\
\hline bla VIM-2 & 98 & $82-113$ \\
\hline
\end{tabular}

Table 3: Limits of detection (LOD) of the RT-PCR assays.

\section{Discussion}

Early identification of carbapenemase producing organisms (CPOs) among clinical isolates should be obligatory to prevent their prevalence. Infections caused by CPOs are the most worrisome because of the high mortality rate. Additionally, carbapenemases genes might disperse rapidly among intestinal microbiota and others bacteria especially easily in hospital environments under antibiotic selective pressure [11].

In the routine laboratory, detection of carbapenem resistant isolates is mainly based on phenotypic methods such as double-disk test (DDT) with EDTA inhibitor to detect metalo-beta-lactamases (MBLs) producers and modified Hodge test (MHT) with phenyl boronic acid as an inhibitor to detect KPC-positive bacteria or modifications of above-mentioned tests $[12,13]$. Temocillin susceptibility is ascertaining to identify OXA-48 producers. These phenotypic methods characterised by different specificity and sensitivity often need technical changes and are time-consuming. Currently, there are commercially available more convenient phenotypic method, Etest to detect MBL producers and the other one for KPC identification $[14,15]$. Recently, many different methods are evaluated to detect CPOs but without differentiation into enzyme type. The first step is similarly in all methods described below. It is based on the in vitro hydrolysis of carbapenem (imipenem, meropenem, ertapenem, less doripenem) by bacterial colonies or their extract. The detection of decreased carbapenem concentration is performed by several different manners. Matrix assisted laser desorption/ionization time-of-flight (MALDI-TOF) mass spectrometry (MS) assays reveals others view in mass spectra of the beta-lactam molecule, its salts, and/or its degradation products [16,17]. Hydrolysis of beta-lactam may be conduct with using a bacterial culture or the extract. CarbaNP is a biochemical test for detection of CPOs directly from bacterial culture, which is detected by changes in $\mathrm{pH}$ values revealed by the indicator bromothymol blue [18]. Carbapenem inactivation method (CIM) is a cost-effective and highly robust method. After incubation disc containing meropenem with tested strain the disc is plated on $\mathrm{MH}$ agar plate inoculated with a susceptible $E$. coli indicator strain. If the tested strain produced a carbapenemase, the meropenem was inactivated allowing uninhibited growth of the $E$. coli indicator strain [19]. Protocol for spectrophotometric detection is more timeconsuming and labor-intensive than methods above. After $18 \mathrm{~h}$ incubation, double centrifugations and sonication the supernatant is used to test for its hydrolysis activity by UV spectrophotometry using imipenem as a substrate at a wavelength of $297 \mathrm{~nm}$ [20].

The new, described method in confrontation to other available in literature such as multiplex RT-PCR with melting curves described by Monteiro or Hofko is a little more expensive but the results are more unequivocal [21,22]. Similarly, Nijhuis provided a multiplex RT-PCR to detect carbapenemase genes by using molecular beacon probes, which are more difficult with interpretations than TaqMan probes [23].

According to our knowledge, this is the first report of a multiplex RT-PCR assay with TaqMan probes to detect such set of enzymes, dedicated for Enterobacteriaceae and non-fermentative bacilli. The experiment is easy to conduct and lasts only about $1 \mathrm{~h}$. Unfortunately, expensive equipment and reagents are required therefore it is solution only for specialist laboratories.

In conclusion, we have described a multiplex RT-PCR assay for identification and partial classification of four selected carbapenemases: VIM, IMP, NDM and KPC. The whole experiment, including DNA isolation and PCR cycling, lasts up to $2 \mathrm{~h}$.

\section{Acknowledgements}

We are grateful to National Medicines Institute for providing the two bacterial strains $P$. aeruginosa WUM_5 and $P$. aeruginosa WUM_6. 


\section{References}

1. Gupta N, Limbago BM, Patel JB, Kallen AJ (2011) Carbapenem-resistant Enterobacteriaceae: epidemiology and prevention. Clin Infect Dis 53: 60-67.

2. Meletis G, Exindari M, Vavatsi N, Sofianou D, Diza E (2012) Mechanisms responsible for the emergence of carbapenem resistance in Pseudomonas aeruginosa. Hippokratia 16: 303-307.

3. Poirel L, Bonnin RA, Nordmann P (2011) Genetic basis of antibiotic resistance in pathogenic Acinetobacter species. IUBMB Life 63 : 1061-1067.

4. Walsh TR, Toleman MA, Poirel L, Nordmann P (2005) Metallo-betalactamases: the quiet before the storm? Clin Microbiol Rev 18: 306-325

5. Bush K, Jacoby GA (2010) Updated functional classification of betalactamases. Antimicrob Agents Chemother 54: 969-976.

6. Chen L, Mediavilla JR, Endimiani A, Rosenthal ME, Zhao Y, et al. (2011) Multiplex real-time PCR assay for detection and classification of Klebsiella pneumoniae carbapenemase gene (bla KPC) variants. J Clin Microbiol 49: 579-585.

7. Mlynarczyk G, Sawicka-Grzelak A, Szymanek K, Buczkowska T, Pazik J, et al. (2009) Resistance to carbapenems among Pseudomonas aeruginosa isolated from patients of transplant wards. Transplant Proc 41: 3258-3260.

8. Lomaestro BM, Tobin EH, Shang W, Gootz T (2006) The spread of Klebsiella pneumoniae carbapenemase-producing $\mathrm{K}$. pneumoniae to upstate New York. Clin Infect Dis 43: e26-28.

9. Mulvey MR, Grant JM, Plewes K, Roscoe D, Boyd DA (2011) New Delhi metallo- $\hat{I}^{2}$-lactamase in Klebsiella pneumoniae and Escherichia coli, Canada. Emerg Infect Dis 17: 103-106.

10. Burns MJ, Valdivia H, Harris N (2004) Analysis and interpretation of data from real-time PCR trace detection methods using quantitation of GM soya as a model system. Anal Bioanal Chem 378: 1616-1623.

11. Hindiyeh M, Smollen G, Grossman Z, Ram D, Davidson Y, et al. (2008) Rapid detection of blaKPC carbapenemase genes by real-time PCR. J Clin Microbiol 46: 2879-2883.

12. Mathers AJ, Carroll J, Sifri CD, Hazen KC (2013) Modified Hodge test versus indirect carbapenemase test: prospective evaluation of a phenotypic assay for detection of Klebsiella pneumoniae carbapenemase (KPC) in Enterobacteriaceae. J Clin Microbiol 51: 1291-1293.

13. Arunagiri K, Sekar B, Sangeetha G, John J (2012) Detection and characterization of metallo-beta-lactamases in Pseudomonas aeruginosa by phenotypic and molecular methods from clinical samples in a tertiary care hospital. West Indian Medical Journal 61: 778-783.

14. Notake S, Matsuda M, Tamai K, Yanagisawa H, Hiramatsu K, et al. (2013) Detection of IMP metallo-ß-lactamase in carbapenem-nonsusceptible Enterobacteriaceae and non-glucose-fermenting Gram-negative rods by immunochromatography assay. J Clin Microbiol 51: 1762-1768.

15. Jaskulski MR, Medeiros BC, Borges JV, Zalewsky R, Fonseca ME, et al. (2013) Assessment of extended-spectrum beta-lactamase, KPC carbapenemase and porin resistance mechanisms in clinical samples of Klebsiella pneumoniae and Enterobacter spp. Int J Antimicrob Agents 42: 76-79.

16. Hrabak J, Chudackova E, Walkova R (2013) Matrix-assisted laser desorption ionization-time of flight (maldi-tof) mass spectrometry for detection of antibiotic resistance mechanisms: from research to routine diagnosis. Clin Microbiol Rev 26: 103-114.

17. Monteferrante CG, Sultan S, Ten Kate MT, Dekker LJ, Sparbier K, et al. (2016) Evaluation of different pretreatment protocols to detect accurately clinical carbapenemase-producing Enterobacteriaceae by MALDI-TOF. J Antimicrob Chemother 71: 2856-2867.

18. Pasteran F, Veliz O, Ceriana P, Lucero C, Rapoport M, et al. (2015) Evaluation of the Blue-Carba test for rapid detection of carbapenemases in gram-negative bacilli. J Clin Microbiol 53: 1996-1998.

19. Rohde H, van der Zwaluw K, de Haan A, Pluister GN, Bootsma HJ, et al (2015) The Carbapenem Inactivation Method (CIM), a simple and lowcost alternative for the Carba NP test to assess phenotypic carbapenemase activity in Gram-negative rods. PLoS One 10:e0123690.

20. Bernabeu S, Poirel L, Nordmann P (2012) Spectrophotometry-based detection of carbapenemase producers among Enterobacteriaceae. Diagn Microbiol Infect Dis 74: 88-90.

21. Monteiro J, Widen RH, Pignatari AC, Kubasek C, Silbert S (2012) Rapid detection of carbapenemase genes by multiplex real-time PCR. J Antimicrob Chemother 67: 906-909.

22. Hofko M, Mischnik A, Kaase M, Zimmermann S, Dalpke AH (2014) Detection of carbapenemases by real-time PCR and melt curve analysis on the BD Max system. J Clin Microbiol 52: 1701-1704.

23. Nijhuis R, Samuelsen O, Savelkoul P, van Zwet A (2013) Evaluation of a new real-time PCR assay (Check-Direct CPE) for rapid detection of KPC, OXA-48, VIM, and NDM carbapenemases using spiked rectal swabs. Diagn Microbiol Infect Dis 77: 316-320. 